\title{
Experimental investigation of the dynamic response of squeeze film dampers made of steel and glass/epoxy
}

\author{
Waleed F. Faris ${ }^{\mathrm{a}, \mathrm{b} *}$, Asad A. Khalid ${ }^{\mathrm{a}}$, A. Albagul $^{\mathrm{b}}$ and Godem A. Ismail ${ }^{\mathrm{b}}$ \\ ${ }^{a}$ Mechanical Engineering Department, International Islamic University Malaysia (IIUM), Jalan Gombak, 53100, \\ KL, Malaysia \\ ${ }^{\mathrm{b}}$ Mechatronics Engineering Department, International Islamic University Malaysia (IIUM), Jalan Gombak, 53100, \\ KL, Malaysia
}

Received 11 December 2006

Revised 31 July 2007

\begin{abstract}
This work is devoted to the fabrication and investigation of the Squeeze Film Dampers (SFDs) which are widely used in many applications. This include the fabrication of a test rig and several dampers with different sizes and two different materials which composite and non-composite. Composite dampers (Glass/epoxy), each consists of 30 layers, were fabricated by hand lay-up method. Outer and inner diameters of all the fabricated dampers were maintained as 60 and $40 \mathrm{~mm}$ respectively. Non-composite dampers (Steel) were fabricated and tested using turning machine. Three dampers of different lengths were examined for both materials. A rotor-bearing system for the analysis has been designed and fabricated. The test rig consists of mild steel shaft, two supports, oil pressure system, and two self-alignment ball bearings were fixed on each end support. Two squeeze film dampers were used for the two support ends. Vibration amplitude has been examined for all the fabricated dampers at different shaft rotational speeds. The first resonance speed was examined for all the dampers tested. Results show that the vibration amplitude of the steel damper was lower than Glass/epoxy dampers with the same L/D ratio. On the other hand, a considerable weight saving has been achieved by using Glass/epoxy composite dampers. It has been found that the performance of squeeze film damper improved with increasing length/diameter ratio (L/D) within the range tested.
\end{abstract}

Keywords: Squeeze film dampers, bearings, vibration, composite materials

\section{Nomenclature}

$$
\begin{array}{ll}
C= & \text { radial clearance }(\mathrm{m}) \\
D= & \text { bearing diameter }(\mathrm{m}) \\
h= & \text { film thickness }(\mathrm{m}) \\
P= & \text { pressure }\left(\mathrm{N} / \mathrm{m}^{2}\right) \\
L= & \text { bearing length }(\mathrm{m}) \\
c / R= & \text { clearance to radius ratio }
\end{array}
$$

\footnotetext{
${ }^{*}$ Corresponding author. E-mail: waleed@iiu.edu.my.
} 


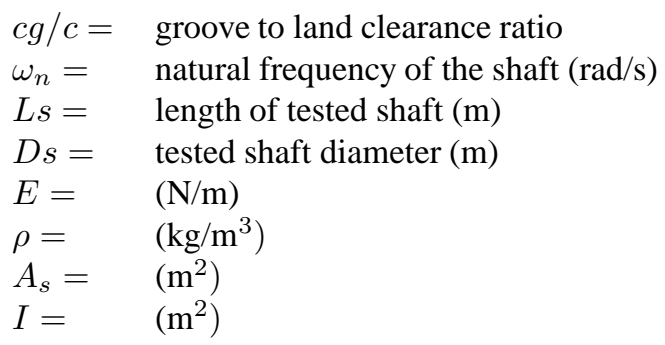

\section{Introduction}

Cooper [1] first published experimental demonstration of the use of a squeeze film for controlling shaft vibrations in 1963. He showed that the problem of "oil whip" can be eliminated by constraining the oil-film journal to prevent rotation. Since Cooper's investigation, the adoption of the SFD for turbo-machinery has increased, extending its application from the original field of aircraft turbine engines to industry. In most aero-engine applications, the purpose of squeeze-film damper is to introduce damping as a series element between the outer race of a rolling element bearing and its rather flexible housing, so that the rotor can safely negotiate any critical speeds and operate smoothly at higher speeds [3]. The vast investigations performed on SFDs have shown that damper force response is greatly influenced by conditions such as: oil feed mechanisms, end seals to restrict axial leakage, levels of inlet (supply) pressure and cavitation pressure of the lubricant, coupling of the damping device to the rotor system, and, in some circumstances, fluid inertia effects. Some experimental investigations involving SFDs with a circumferential feeding-groove have reported significant levels of dynamic pressure at the groove as well as higher damping capacity than that predicted by a classical theory [6], observed dynamic pressures at a circumferential groove of magnitudes about $1 / 3$ of those measured at the thin film lands. The damper configuration tested has a c/R ratio of 0.025 and a groove to land clearance ratio $(\mathrm{cg} / \mathrm{c})$ equal to 5 [7]. also measured circumferential feeding groove dynamic pressures of magnitudes as large as 60 percent of those recorded at the film lands. For this investigation the (c/R) and (cg/c) ratios were 0.0072 and 7 respectively.

Advanced polymer composites are finding increased use in a wide range of both low- and high-technology engineering applications. Composites offer a number of distinct advantages over more conventional engineering materials, such as aluminum and steel. These include higher specific strengths and stiffness, superior corrosion resistance as well as improved fatigue properties. Coupled with these improvements in overall performance, it is the fact that the cost of manufacturing components from fiber-reinforced plastics is often less than that of more conventional metals. Most of the components usually designed are static components and often non-load bearing components. But focus by designers is now shifted to critically loaded structural components such as discs, blades, etc. In early stages composite shafts were operated in the sub critical region. A high performance rotating machinery is towards higher operating speeds leading inevitably to supercritical operation of such shafts that gives rise to issues of vibration, stability and stress. A study by Ingle R. B A. [4], on a composite shaft made of carbon-epoxy made for the high speed CNC grinding machines and the centrifuges has been carried out. The shaft has been manufactured with 16 layers having stacking angles $\left[0^{\circ} / 90^{\circ} / 45^{\circ} /-45^{\circ}\right]_{2 \mathrm{~s}}$ using filament winding process. Static and dynamic analysis and performance characteristics of the carbon-epoxy shaft in aerostatic conical journal bearing at high speeds in the range of 10,000-65,000 rpm. Another study on a novel composite coupling has been carried out proposed by Ghoneim $\mathrm{H}$ [2] for a flexible hyperbolic composite coupling. In addition to enjoying the advantages of composite materials, the composite coupling proposed to provide some of the needed damping and can be readily integrated with a composite drive shaft into a single unit.

The main objectives of this study are to study the effect of using Glass/epoxy composite squeeze film dampers on vibration response of a rotor-bearing system. This would include the vibration amplitude, eccentricity ratio, and effect of length/diameter (L/D) ratio, also to compare the result with the mild steel squeeze film dampers. Resonance speed at $1^{\text {st }}$ mode examined also for all the tested dampers.

Khalid et al. [5] carried out a similar experiment comparing steel and Teflon as potential squeeze dampers. The current work is a continuation on proposing new materials for squeeze dampers and characterizing their dynamic performance within rotor-shaft systems experimentally. 


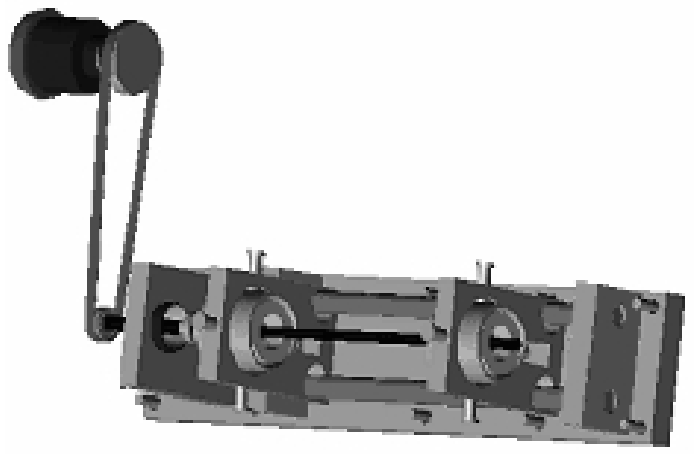

Fig. 1. The test rig.

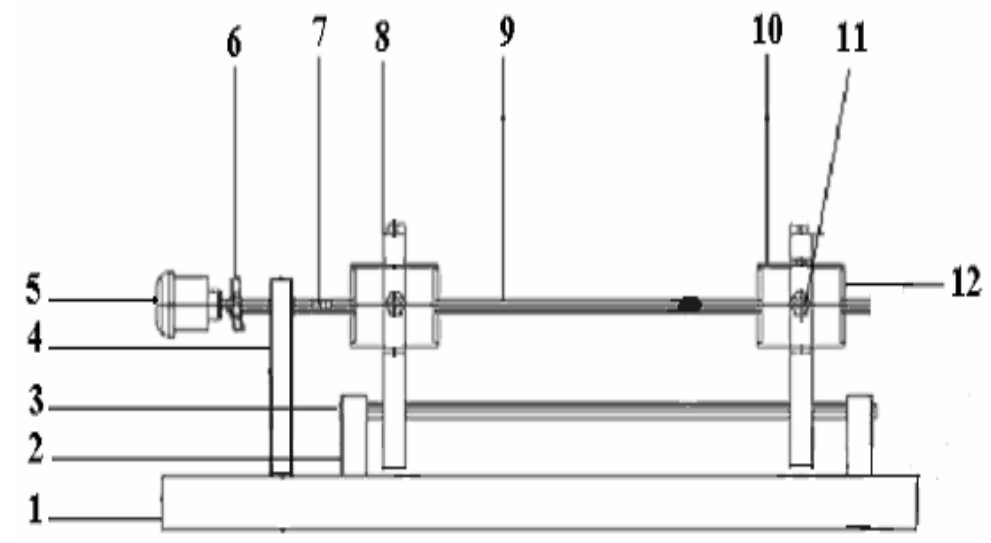

Fig. 2. Schematic diagram.

\section{Experimental setup}

\subsection{Test rig design and fabrication}

AutoCAD Mechanical software has been used to design a model for the test rig as shown in Fig. 1. A schematic diagram of the designed test rig is shown in Fig. 2. It consists of General base (1), it is a plate steel and fixed to the ground and an absorber is placed between the plate and the flour. Base support (2), it is divided into two parts, the first part is fixed on the general support by two bolts and the second part is fixed on the two support shafts which are mounted between them. Support Shafts (3), they are two shafts of steel and the use of these support shafts are to hold the bearing support and to provide a variable distance between the two bearing system. Motor support (4), it is assembled with self-alignment ball bearing and fixed on the general support. Electrical motor (5), this motor is used to provide the required rotational speed to the test shaft. Pulley system (6), this system is used to increase the test shaft speed to $10.000 \mathrm{rpm}$. Flexible coupling (7), it is used to transmit the motion to the test rig shaft. Bearing support (8), two bearing supports are mounted on the support shaft in both sides. The use of these supports is to support the rotor bearing system to operate properly. Tested shaft (9), it is a steel shaft with $12 \mathrm{~mm}$ diameter and $760 \mathrm{~mm}$ length. It is supported by two fabricated squeeze film bearing on both ends. Bearing case/hosing (10), the bearing case is used for holding the squeeze film damper. There also a thin oil film layer between the bearing case and damper. Bolts (11) there are four bolts in each side (in each bearing support), the use of these bolts to align the shaft. Squeeze film damper (12), it is the fabricated dampers with self-alignment ball bearing inside each damper. Vibration response was taken by two transducers connected to the bearing case in $\mathrm{X}$ and $\mathrm{Y}$ directions. The response is sent to the data acquisition system and be analyzed by the DASY LAB software. 
Table 1

Fabricated dampers specification

\begin{tabular}{cccccc}
\hline No & Material & L/D ratio & \multicolumn{3}{c}{ Damper parameters } \\
\cline { 3 - 6 } & & & Length $(\mathrm{mm})$ & Outer diameter (mm) & Dampers weight $(\mathrm{g})$ \\
\hline$(1)$ & Steel & 0.3 & 18 & 60 & 350 \\
& & 0.5 & 30 & 60 & 560 \\
& & 42 & 60 & 760 \\
2 & 0.7 & 18 & 60 & 67 \\
& \multirow{3}{*}{ Glass } & 0.3 & 30 & 60 & 106 \\
& 0.5 & 42 & 60 & 155 \\
\hline
\end{tabular}

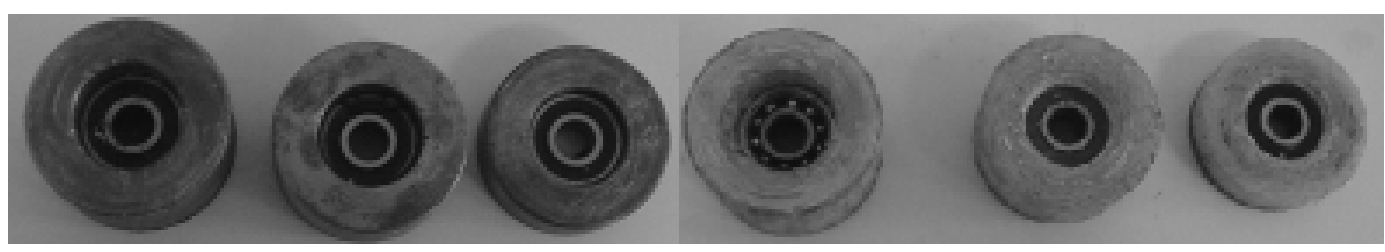

a)

b)

Fig. 3. Fabricated dampers a) Steel dampers b) Glass/epoxy dampers.

\subsection{Dampers fabrication}

Steel and Glass/epoxy dampers was fabricated using turning machine. Samples of the fabricated dampers are shown in Fig. 3. Two "O" rings seals were used for each damper to provide the required damper length and to prevent the oil from coming out from the damper surface. The fabricated dampers specification is shown in Table.

\section{Experimental results}

\subsection{Natural frequency of the shaft}

The natural frequency of the shaft has been determined for the simply supported shaft using the following Equation:

$$
\omega_{n}=(n \pi)^{2} \sqrt{\frac{E I}{\rho A_{s} L_{s}^{4}}}
$$

Where:

$n=1$ for the first mode

$\omega_{n}=$ natural frequency of the shaft $(\mathrm{rad} / \mathrm{s})$

Then the natural frequency for the test shaft having the following specification:

$\mathrm{Ls}=0.700 \mathrm{~m}, \mathrm{Ds}=0.012 \mathrm{~m}, \mathrm{E}=207 \times 10^{9} \mathrm{~N} / \mathrm{m}, \rho=7840 \mathrm{~kg} / \mathrm{m}^{3}$

$\mathrm{A}_{s}=\pi(0.012)^{2} / 4=1.150 \times 10^{-4} \mathrm{~m}^{2}$

$\mathrm{I}=\pi(0.012)^{4} / 64=1.05 \times 10^{-9} \mathrm{~m}^{2}$

Is:

$$
\begin{aligned}
\omega_{n} & =(\pi)^{2} \sqrt{\frac{\left(207 \times 10^{9}\right) \times\left(1.05 \times 10^{-9}\right)}{(7840) \times\left(1.15 \times 10^{-4}\right) \times(0.7)^{4}}} \\
\omega_{n} & =312.74 \mathrm{rad} / \mathrm{sec} \\
\omega_{n} & =312.74 \times 9.54=2983.5 \mathrm{rpm}
\end{aligned}
$$

Figure 4 shows the vibration amplitude of the fabricated simply supported shaft. The response was taken in $x$ and $y$ directions. As shown from this Figure, displacement in $y$ direction is higher than that in the $x$ direction at all the 


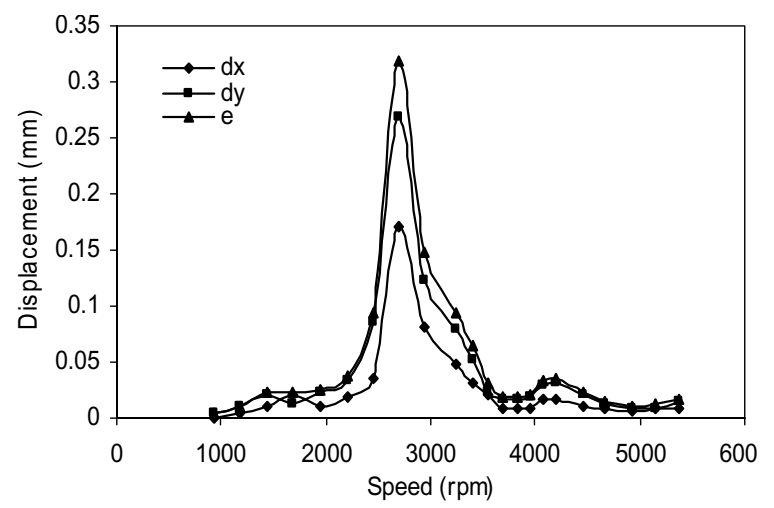

Fig. 4. Speed - Displacement relation for simply supported shaft (mild steel shaft of $0.7 \mathrm{~m}$ length).

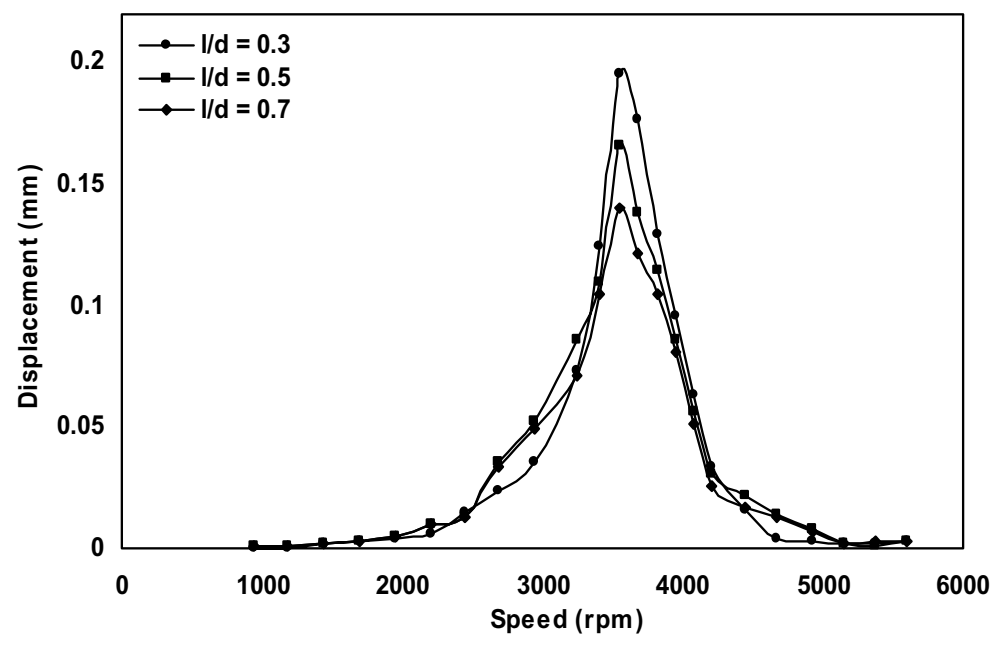

Fig. 5. L/D ratio effect on vibration amplitude (steel damper).

test shaft rotational speeds. Also, resultant displacement $e$ is shown. Experimentally, the resonance frequency of the shaft was found to be $2800 \mathrm{rpm}$. The difference between theoretical and experimental values of the frequency was found to be $6.15 \%$. This might be to different reasons related to assembly or material inhomogeneity because the theoretical equation assumes a perfect shaft with homogeneous material

As shown in Figs 5 and 6, with increasing the L/D ratio from 0.3 to 0.7, the vibration amplitude decreased. The vibration amplitude at resonance decreased about $28.38 \%$ for steel damper and about $10.94 \%$ for Glass/epoxy damper, which means L/D ratio affected Steel damper than Glass/epoxy damper, on the other hand the L/D ratio introduced more weight on Steel damper than on Glass/epoxy damper.

Figures 7, 8 and 9 show the effect of damper material with different (L/D) ratio on vibration amplitude. As shown in these figures the amplitude of vibration reduced by $37.73 \%, 33.41 \%$, and $40.24 \%$ for Steel damper with L/D ratio $0.3,0.5$, and 0.7 respectively compared with Glass/epoxy damper with the same L/D ratio. On the other hand saving weight by $80.86 \%, 81.10 \%$, and $79.61 \%$ achieved by using Glass/epoxy damper with L/D ratio $0.3,0.5$, and 0.7 respectively.

\section{Conclusion}

Dampers and The test rig have been designed and fabricated carefully. Three different length-diameter (L/D) ratio dampers for each material were tested to study the effect of (L/D) ratio on both materials. Rotational speed at 


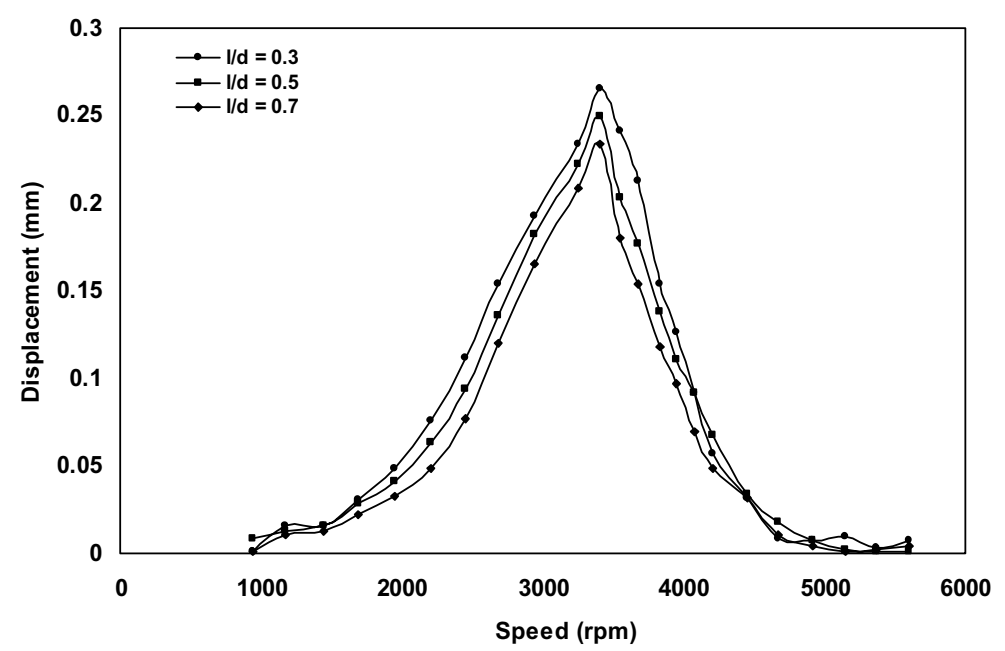

Fig. 6. L/D ratio effect on vibration amplitude (glass/epoxy damper).

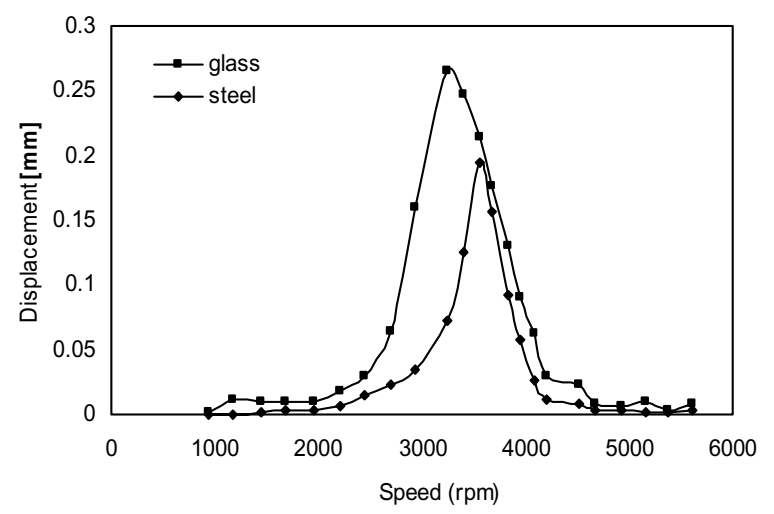

Fig. 7. Damper material effect on vibration amplitude $(\mathrm{L} / \mathrm{D}=0.3)$.

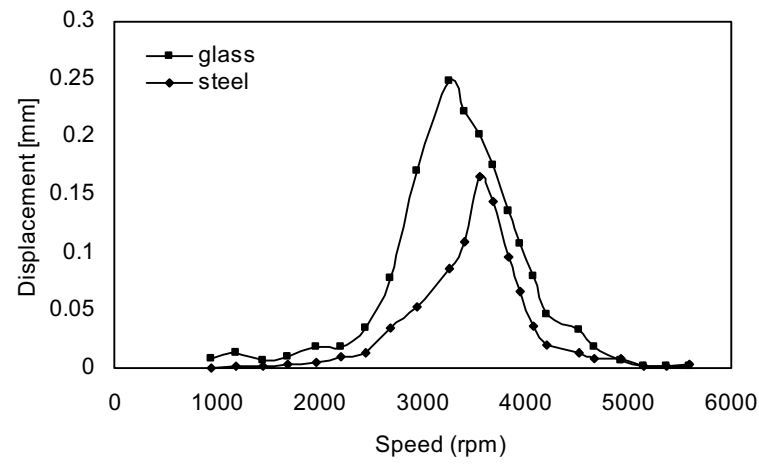

Fig. 8. Damper material effect on vibration amplitude $(\mathrm{L} / \mathrm{D}=0.5)$.

resonance frequency was found to be 2703 with an acceptable error of $6.15 \%$. Results show that the vibration response in $y$-direction was higher than in $x$ direction for both steel and Glass/epoxy dampers and with increasing (L/D) ratio for the range tested, the vibration amplitude improved $28.38 \%$ for steel damper and $10.94 \%$ for Glass/epoxy damper. From results, it is clear that (L/D) ratio affected the steel dampers more than the Glass/epoxy dampers. 


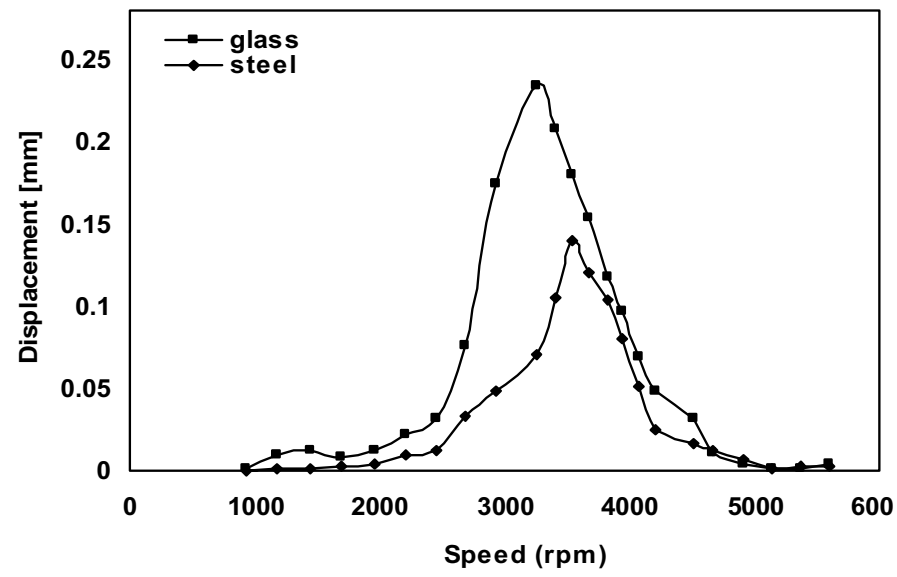

Fig. 9. Damper material effect on vibration amplitude $(\mathrm{L} / \mathrm{D}=0.7)$.

The amplitude of vibration reduced by $37.73 \%, 33.41 \%$, and $40.24 \%$ for Steel damper with L/D ratio 0.3, 0.5, and 0.7 respectively compared with Glass/epoxy damper with the same L/D ratio. On the other hand saving weight by $80.86 \%, 81.10 \%$, and $79.61 \%$ achieved by using Glass/epoxy damper with L/D ratio $0.3,0.5$, and 0.7 respectively.

\section{References}

[1] S. Cooper, Preliminary Investigation of Oil Films for the Control of Vibration, Paper 28, Proceedings of the Lubrication and Wear Convention, Instn. Mech. Engrs., UK, (1963).

[2] H. Ghoneim and D.J. Lawrie, Dynamic analysis of a hyperbolic composite coupling, Journal of Sound and Vibration 301(1) (2007), 43-58.

[3] R. Holmes and M. Dogan, The Performance of a Sealed Squeeze Film Bearing in Flexible Support Structure, (Vol. 199), Proc. Institution of Mechanical Engineers, 1985, 1-9.

[4] R.B. Ingle and B.B. Ahuja, An experimental investigation on dynamic analysis of high speed carbon - epoxy shaft in aerostatic conical Journal bearings, Composites Science and Technology 66(3) (2006), 604-612.

[5] A.A. Khalid, A. Albagul, W. Faris and G. Ismail, An Experimental Study on Steel and Teflon Squeeze Film dampers, Shock and Vibration 13 (2006), 33-40.

[6] L. San Andres and J.M. Vance, Experimental Measurement of the Dynamic pressure Distribution in a Squeeze Film Damper Executing Circular Centered Orbits, ASLE, Transactions 30(3) (1987), 373-383.

[7] F.Y. Zeidan and J.M. Vance, Cavitation Regimes in Squeeze Film Dampers and Their Effect on the Pressure Distribution, STLE Tribology Transactions 33(3) (1990), 447-453, (1990). 

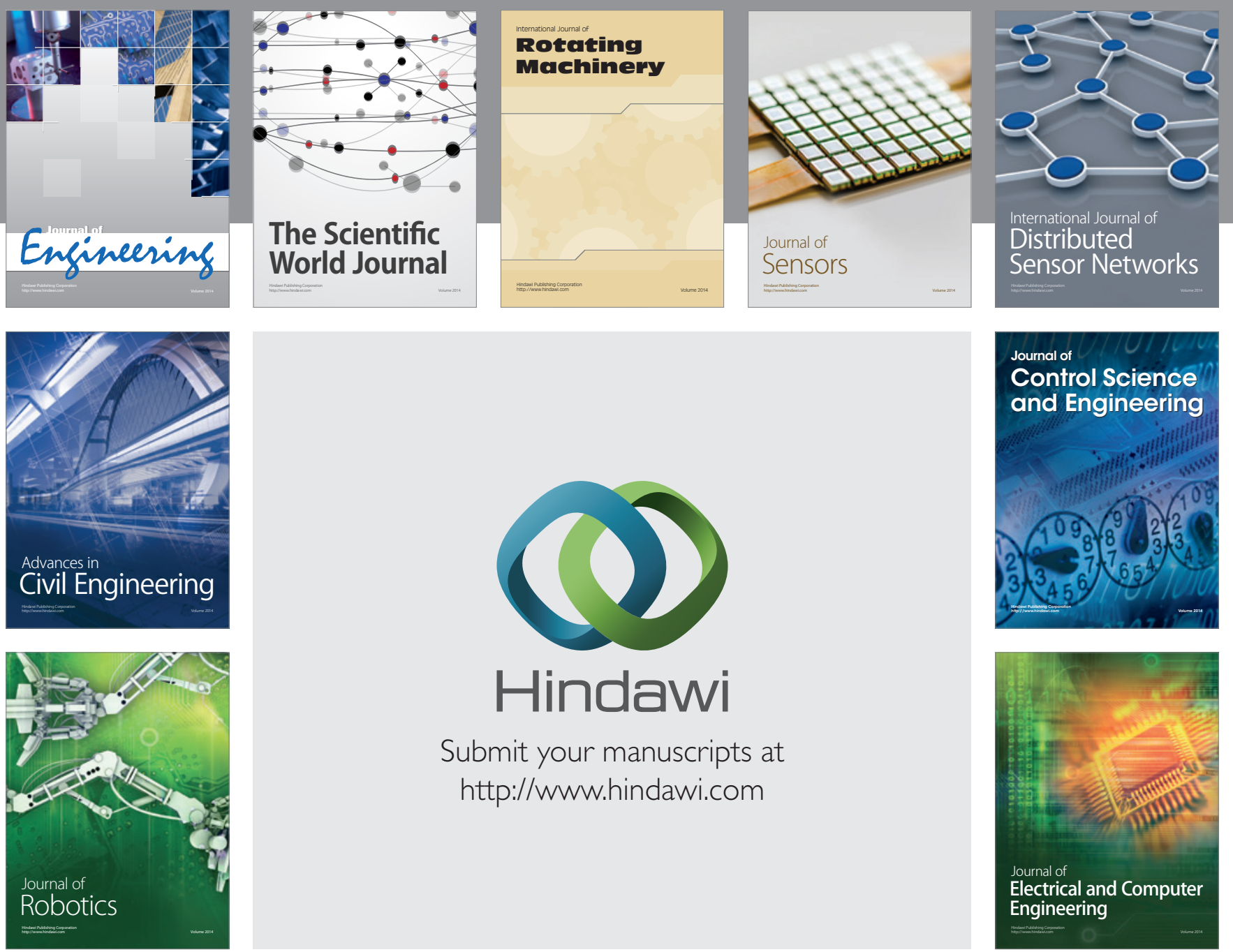

Submit your manuscripts at

http://www.hindawi.com
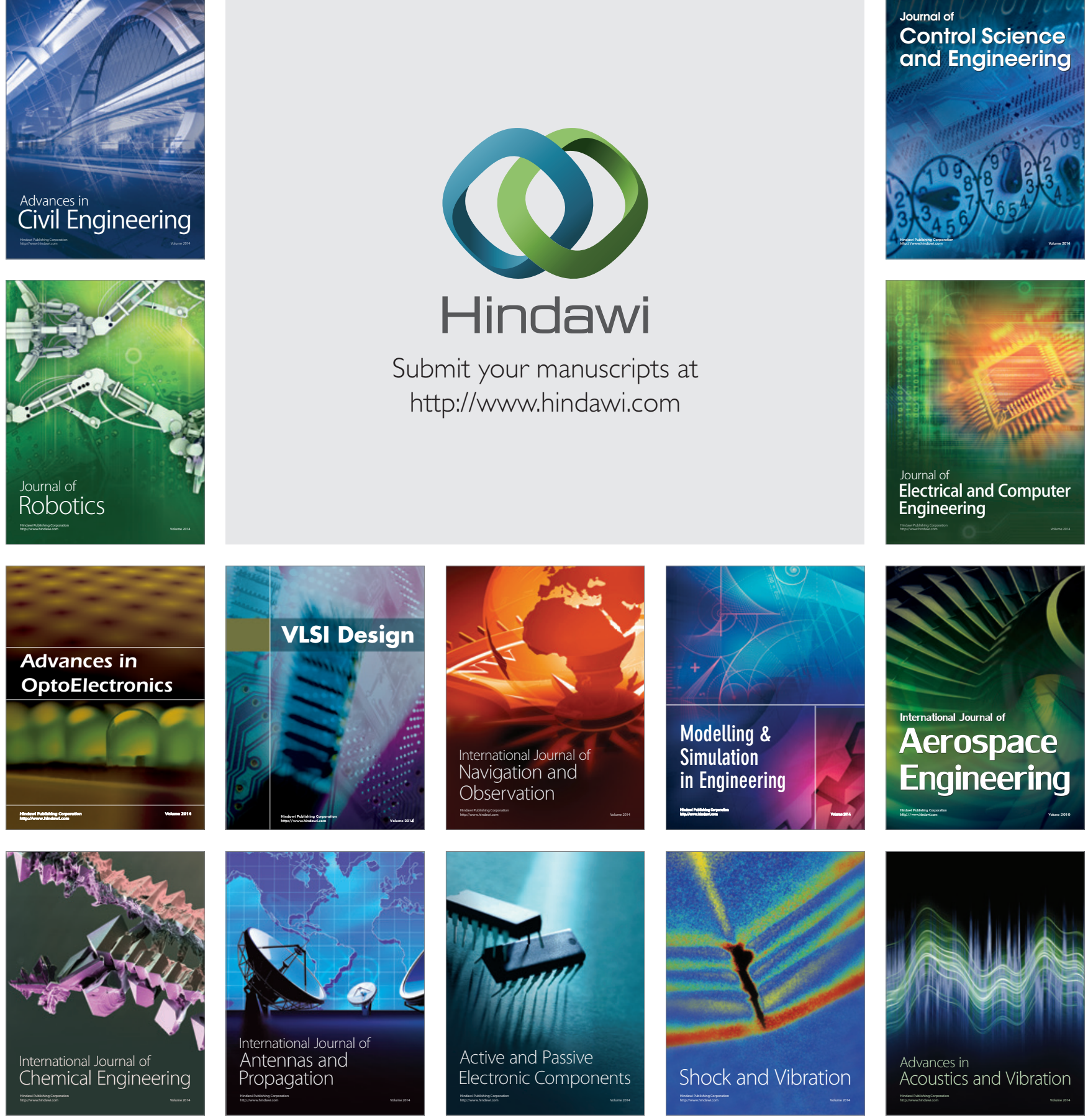